\title{
Regulated Intramembrane Proteolysis
}

National Cancer Institute

\section{Source}

National Cancer Institute. Regulated Intramembrane Proteolysis. NCI Thesaurus. Code C95245.

A process that involves the proteolysis of an integral membrane protein at a site that is within its transmembrane domain. This cleavage causes the release of cytosolic fragments that can enter the nucleus and regulate transcription. 